\title{
A social work study on the effect of quality of life improvement on reduction of work-family and family-work conflicts
}

\author{
Masoumeh Emami ${ }^{a^{*}}$, Mohammad Reza Abedi $^{\text {b }}$ and Afsaneh Javadzadeh ${ }^{\mathrm{c}}$
}

${ }^{a}$ MS Student, Counseling Department, Islamic Azad University of Khomeinishahr, Khomeinishahr Branch, Daneshjou Blvd, Iran

${ }^{b}$ Associate Professor, Department of Counseling, University of Isfahan, Isfahan, Iran

${ }^{c}$ Assistant Professor, Counseling Department, Islamic Azad University of Khomeinishahr, Khomeinishahr Branch, Daneshjou Blvd, Iran

\section{H R O N I C L E}

Article history:

Received May 2, 2013

Received in revised format

25 June 2013

Accepted 7 July 2013

Available online

July 112013

Keywords:

Work-family conflict

Family-work conflict

Quality of life

\section{A B S T R A C T}

\begin{abstract}
This paper investigates whether a quality improvement program can reduce workfamily and family-work conflicts or not. The proposed study of this paper selects 30 female employees of municipality of Tehran, Iran and divides them into two groups of test and control group. The first group is asked to participate in eight 90-minute sessions of quality improvement program and after the program ends, both groups are requested to fill in Netemeyer's work-family questionnaire. We then analyze the results using different statistical tests. The results of our survey indicate that quality improvement program statistically improves quality of life among the first group in reducing the work-family as well as family-work conflicts $(\mathrm{P}<0.01)$.
\end{abstract}

\section{Introduction}

These days, women and men often have to work together in order to reach a more stable level of life. Although married women's jobs often help them find independent economic condition, there are some negative consequences, which may prevent them on contributing to their family, more effectively (Bellavia \& Frone, 2005). In many cases, a comprehensive quality improvement program helps reduce such conflicts. Thomas and Ganster (1995) investigated the impact of family-supportive work variables on work-family conflict and strain. Netemeyer et al. (1996) reported a 3-sample study that developed and validated short, self-report scales of work-family conflict (WFC) and familywork conflict (FWC). They developed the scales and test dimensionality and internal consistency, which have become as one of the most popular methods for WFC programs.

*Corresponding author. Tel: +989122445491

E-mail address: Masoumeh.Emami @iaukhsh.ac.ir (M. Emami)

(c) 2013 Growing Science Ltd. All rights reserved. doi: $10.5267 /$ j.ms 1.2013 .07 .009 
Thompson et al. (1999) investigated on the events that work-family benefits are not enough by looking into the influence of work-family culture on benefit utilization, organizational attachment, and work-family conflict. Carlson et al. (2000) provided a multidimensional measure of workfamily conflict. Frone et al. (1997) developed and examined an integrative model of the work-family interface. They extended prior research by explicitly distinguishing between work interfering with family and family interfering with work. This distinction help them test different hypotheses concerning the unique antecedents and outcomes of both forms of work-family conflict and a reciprocal relationship among them. They also examined the effect of gender, race, and job kind on their generalizability of the model based on some data gathered through household interviews with a random sample of 631 individuals and reported promissing results. They also indicated that although the model was invariant across gender and race, there were some differences across blue- and whitecollar workers.

Ernst Kossek and Ozeki (1998) provided a review and directions for organizational behavior-human resources research WFC, policies, and the job-life satisfaction relationship. Gutek et al. (1991) proposed two conflicting frameworks for understanding work-family conflict. According to the rational view, conflict was associated with linearly to the total amount of time spent in paid and family work. According to the gender role perspective, gender role expectations mute the relationship between hours expended and perceived WFC, and gender interacts with number of hours worked and WFC. Two measures of WFC were applied to assess, respectively, work interference with family and family interference with work. The results generally supported the usefulness of separate indicators of WFC and advantages of both the rational view and the gender role view.

Michel et al. (2009) performed a comparative test of WFC models and critical examination of workfamily linkages. Michel et al. (2010) explained that although work and family social support predict role stressors and WFC, there has been much ambiguity regarding the conceptual relationships among these constructs. Palmer et al. (2012) investigated conflict between work and family among New Zealand teachers with dependent children by investigating teachers' use of parenting programmes and programme preferences. Ferguson et al. (2012) performed a two-study examination of work-family conflict, production deviance and gender.

\section{The proposed study}

In this paper, we investigate whether a quality improvement program can reduce work-family and family-work conflicts or not. The proposed study of this paper selects 30 female employees of municipality of Tehran and divides them into two groups of test and control group. The first group is asked to participate in eight sessions of 90 minutes quality improvement program and after the program ends, both groups are requested to fill in a questionnaire developed by Netemeyer et al. (1996). When then analyze the results using different statistical tests. The proposed study considers two hypotheses as follows,

1. A quality improvement program can reduce work-family conflict (WFC).

2. A quality improvement program can reduce family-work conflict (FWC).

The proposed study use basic statistical tests as well as ANOVA test to verify two hypotheses of this survey.

\section{The results}

In this section, we present details of our findings on testing two hypotheses of this survey. 


\subsection{The first hypothesis: The relationship between quality improvement program and WFC}

The first hypothesis of this survey investigates whether a good quality improvement program could reduce WFC or not. Table 1 demonstrates the summary of some basic statistics associated with test and control groups.

\section{Table 1}

The summary of statistics associated with the effect of quality improvement program on WFC

\begin{tabular}{llccccc}
\hline & Stage & Number & Mean & Standard deviation & $\min$ & $\max$ \\
\hline \multirow{2}{*}{ Test } & Pre-test & 12 & 25.53 & 4.67 & 12 & 31 \\
& Post-test & 12 & 24.07 & 4.60 & 12 & 30 \\
\hline \multirow{2}{*}{ Control } & Pre-test & 15 & 24.93 & 5.90 & 15 & 33 \\
& Post-test & 16 & 24.90 & 5.80 & 16 & 33 \\
\hline
\end{tabular}

In addition, Table 2 demonstrates the summary of ANOVA test on pre-test and group.

Table 2

The summary of ANOVA test on testing the first hypothesis

\begin{tabular}{llcccccc}
\hline Source of change & Sum of squares & df & Mean of squares & F & Sig. & Eta & Power \\
\hline Pre-test & 740.94 & 1 & 74.94 & 742.98 & 0.001 & 0.96 & 1 \\
Group & 15.66 & 1 & 15.66 & 15.7 & 0.001 & 0.96 & 0.96 \\
\hline Error & 26.92 & 27 & 0.99 & & & & \\
\hline
\end{tabular}

As we can observe from the results of Table 1 and Table 2, we have obtained meaningful results when the level of significance is one percent. Therefore, we can confirm the first hypothesis of this survey.

\subsection{The second hypothesis: The relationship between quality improvement program and FWC}

The second hypothesis of this survey studies whether a good quality improvement program could reduce FWC or not. Table 3 presents the summary of some basic statistics associated with test and control groups.

Table 2

The summary of statistics associated with the effect of quality improvement program on FWC

\begin{tabular}{llccccc}
\hline \multirow{2}{*}{ Test } & Stage & Number & Mean & Standard deviation & $\min$ & $\max$ \\
& Pre-test & 15 & 24.00 & 3.22 & 19 & 29 \\
& Post-test & 15 & 24.47 & 3.20 & 17 & 28 \\
\hline \multirow{2}{*}{ Control } & Pre-test & 15 & 24.27 & 3.67 & 18 & 30 \\
& Post-test & 15 & 25.00 & 3.54 & 20 & 31 \\
\hline
\end{tabular}

Once again, Table 4 shows the summary of ANOVA test on pre-test and group for the second hypothesis of this survey.

Table 4

The summary of ANOVA test on testing the second hypothesis

\begin{tabular}{llcccccc}
\hline Source of change & Sum of squares & df & Mean of squares & F & Sig. & Eta & Power \\
\hline Pre-test & 281.36 & 1 & 281.39 & 198.18 & 0.001 & 0.88 & 1 \\
Group & 39.23 & 1 & 39.24 & 27.62 & 0.001 & 0.45 & 0.98 \\
\hline Error & 38.33 & 27 & 1.42 & & & & \\
\hline
\end{tabular}


As we can observe from the results of Table 3 and Table 4, we have reached some meaningful results when the level of significance is one percent. Therefore, we can confirm the second hypothesis of this survey.

\section{Conclusion}

There is no doubt that a good society needs happy family relationship and this could happen when both husband and wife could accomplish their responsibly, properly. In Iran, women are expected to prepare food and grow children. However, these responsibilities are challenged when they have to work outside. In this paper, we have performed an investigation to find out whether it is possible to reduce such conflicts by asking women to participate in some quality improvement programs. The results of this survey have indicated that when women participated in such programs, they could manage to handle existing conflicts on work-family as well as family-work conflicts.

\section{Acknowledgment}

The authors would like to thank the anonymous referees for cordially helping us improve the quality of our work.

\section{References}

Bellavia, G. M., \& Frone, M. R. (2005). Work-family conflict. Handbook of work stress, 113-147.

Carlson, D. S., Kacmar, K. M., \& Williams, L. J. (2000). Construction and initial validation of a multidimensional measure of work-family conflict. Journal of Vocational Behavior, 56(2), 249276.

Ernst Kossek, E., \& Ozeki, C. (1998). Work-family conflict, policies, and the job-life satisfaction relationship: A review and directions for organizational behavior-human resources research. Journal of applied psychology, 83(2), 139.

Ferguson, M., Carlson, D., Hunter, E., \& Whitten, D. (2012). A two-study examination of workfamily conflict, production deviance and gender. Journal of Vocational Behavior, 81(2), 245-258.

Frone, M. R., Yardley, J. K., \& Markel, K. S. (1997). Developing and testing an integrative model of the work-family interface. Journal of Vocational Behavior,50(2), 145-167.

Gutek, B. A., Searle, S., \& Klepa, L. (1991). Rational versus gender role explanations for workfamily conflict. Journal of applied psychology, 76(4), 560.

Michel, J. S., Mitchelson, J. K., Kotrba, L. M., LeBreton, J. M., \& Baltes, B. B. (2009). A comparative test of work-family conflict models and critical examination of work-family linkages. Journal of Vocational Behavior, 74(2), 199-218.

Michel, J. S., Mitchelson, J. K., Pichler, S., \& Cullen, K. L. (2010). Clarifying relationships among work and family social support, stressors, and work-family conflict. Journal of Vocational Behavior, 76(1), 91-104.

Netemeyer, R. G., Boles, J. S., \& McMurrian, R. (1996). Development and validation of work-family conflict and family-work conflict scales. Journal of applied psychology, 81(4), 400.

Palmer, M., Rose, D., Sanders, M., \& Randle, F. (2012). Conflict between work and family among New Zealand teachers with dependent children. Teaching and Teacher Education, 28(7), 10491058.

Thomas, L. T., \& Ganster, D. C. (1995). Impact of family-supportive work variables on work-family conflict and strain: a control perspective. Journal of applied psychology, 80(1), 6 .

Thompson, C. A., Beauvais, L. L., \& Lyness, K. S. (1999). When work-family benefits are not enough: The influence of work-family culture on benefit utilization, organizational attachment, and work-family conflict. Journal of vocational behavior, 54(3), 392-415. 